\section{The Conclusion of the BEIR VII Report Endorsing the Linear No-Threshold Model Is No Longer Valid Due to Advancement of Knowledge}

TO THE EDITOR: I read with interest the Invited Perspective by Duncan et al. (1), which was in response to the article by Siegel et al. (2) criticizing the Biologic Effects of Ionizing Radiation (BEIR) VII report's endorsement of the linear no-threshold (LNT) model for radiation-induced cancer. Duncan et al. stated that the BEIR VII report provided a detailed case against a low-dose threshold, referring to the linearity of dose response in the atomic bomb survivor cancer data. However, the Ozasa et al. update (3) to the atomic bomb survivor cancer mortality data has shown significant curvature in the dose-response relationship in the 0-2 Gy range. This curvature is inconsistent with the LNT model but consistent with radiation hormesis (4). The Grant et al. update (5) to the cancer incidence data of the atomic bomb survivors has also shown significant curvature in the dose-response relationship that would not be consistent with the LNT model. Thus, the main epidemiologic evidence quoted in the BEIR VII report no longer supports the LNT model.

Duncan et al. also stated that a threshold dose could exist only if the repair mechanisms after exposure to low-dose radiation leave no cells harboring DNA mutations. In making such a statement, the authors did not consider the larger amount of DNA damage that occurs due to endogenous causes. Because low-dose radiation enhances defenses such as DNA repair enzymes, there would be reduced endogenous DNA damage in the period after exposure to low-dose radiation (6), and the ultimate result would be reduced overall DNA damage and mutations, as has been observed in mice, for example (7). Therefore, even though DNA repair mechanism is imperfect, there would be reduction of overall DNA damage after low radiation exposures.

In addition, Duncan et al. did not address the point raised by Siegel et al. (2) of the importance of the immune system deficiency as the cause of cancer. For example, with the suppression of the immune system, cancer mortality rate increased nearly 80fold in young organ-transplant patients $(8)$, and cancer incidence rate increased nearly 40 -fold in young AIDS patients (9). Such data demonstrate the extreme importance of the immune system in preventing cancers. Therefore, low-dose radiation, which has an immune-enhancing effect, would reduce cancers (10).

In summary, the atomic bomb survivor data, with the updates, are inconsistent with the LNT model. The arguments presented by Duncan et al. (1) for the LNT model are invalid due to incomplete consideration of biologic response to low radiation exposures and the neglect of the importance of the immune system in preventing cancers.

\section{REFERENCES}

1. Duncan JR, Lieber MR, Adachi N, Wahl RL. Radiation dose does matter: mechanistic insights into DNA damage and repair support the linear no-threshold model of low-dose radiation health risks. J Nucl Med. 2018;59:1014-1016.

COPYRIGHT @ 2018 by the Society of Nuclear Medicine and Molecular Imaging.
2. Siegel JA, Greenspan BS, Maurer AH, et al. The BEIR VII estimates of low-dose radiation health risks are based on faulty assumptions and data analyses: a call for reassessment. J Nucl Med. 2018;59:1017-1019.

3. Ozasa K, Shimizu Y, Suyama A, et al. Studies of the mortality of atomic bomb survivors, report 14, 1950-2003: an overview of cancer and noncancer diseases. Radiat Res. 2012;177:229-243.

4. Doss M. Linear no-threshold model vs. radiation hormesis. Dose Response. 2013; 11:480-497.

5. Grant EJ, Brenner A, Sugiyama H, et al. Solid cancer incidence among the life span study of atomic bomb survivors: 1958-2009. Radiat Res. 2017;187:513-537.

6. Pollycove M, Feinendegen LE. Radiation-induced versus endogenous DNA damage: possible effect of inducible protective responses in mitigating endogenous damage. Hum Exp Toxicol. 2003;22:290-306.

7. Osipov AN, Buleeva G, Arkhangelskaya E, Klokov D. In vivo gamma-irradiation low dose threshold for suppression of DNA double strand breaks below the spontaneous level in mouse blood and spleen cells. Mutat Res. 2013;756:141-145.

8. Acuna SA, Fernandes KA, Daly C, et al. Cancer mortality among recipients of solid-organ transplantation in Ontario, Canada. JAMA Oncol. 2016;2:463-469.

9. Biggar RJ, Frisch M, Goedert JJ. Risk of cancer in children with AIDS. AIDSCancer Match Registry Study Group. JAMA. 2000;284:205-209.

10. Liu SZ. On radiation hormesis expressed in the immune system. Crit Rev Toxicol. 2003;33:431-441.

\author{
Mohan Doss \\ Fox Chase Cancer Center \\ 333 Cottman Ave. \\ Philadelphia, PA 19111 \\ E-mail: mohan.doss@fccc.edu
}

Published online Aug. 2, 2018.

DOI: 10.2967/jnumed.118.217489

\section{Challenges to the Paper "Radiation Dose Does Matter: Mechanistic Insights into DNA Damage and Repair Support the Linear No-Threshold Model of Low-Dose Radiation Health Risks"}

TO THE EDITOR: The recent article by Duncan et al. (1) challenges the contentions of Siegel et al. (2) regarding the validity of the Biologic Effects of Ionizing Radiation (BEIR) VII report (3) and its underlying linear no-threshold (LNT) assumption. Duncan et al. contend that Siegel et al. fail to appreciate the appropriateness of the BEIR VII report and its LNT basis. In particular, Duncan et al. conclude:

However, the linear no-threshold model remains the best, and certainly the most conservative, means of estimating the risk of exposing humans to varied levels of ionizing radiation. When considering the risks at low levels of exposure, the BEIR VII report rightfully shifted from an epidemiologic to a mechanistic approach. The BEIR VII report also appropriately considered and rejected the possibility of a threshold.

Rather than repeating the DNA arguments of Duncan et al. and Siegel et al. $(1,2)$, this letter provides commentary that adds additional support for challenging BEIR VII (3) in general, and its underlying LNT hypothesis in particular. The following 4 arguments support the Siegel et al. contentions and further challenge the commentary of Duncan et al. and BEIR VII:

1. BEIR VII includes only a portion of the relevant dosimetric data (i.e., high-dose and dose rate data from the atomic 